\title{
EMPLOYMENT OF RECOVERED TUBERCULOUS PATIENTS
}

\author{
BY \\ A. BARR \\ Oxford Regional Hospital Board, formerly Northern Ireland Tuberculosis Authority, Belfast
}

Under ideal conditions, successful treatment for tuberculosis should be followed by a period of rehabilitation during which the patient gradually returns to full-time suitable employment. Often, however, for economic and other reasons, the provision of adequate facilities for rehabilitation is not easily realized and consequently many patients are left more or less to their own initiative in finding subsequent remunerative work. With a view to discovering what happens in such circumstances, a postal survey of recovered tuberculous patients was carried out recently in Northern Ireland.

In Northern Ireland there are at present no Remploy factories or village settlement for tuberculous patients. A small rehabilitation department has been established by the Northern Ireland Tuberculosis Authority, but apart from this, little exists to meet this particular need. The group surveyed, therefore, represents patients who have been left to their own devices in the post-recovery period.

\section{MATERIAL}

From the beginning of 1948 (the first complete calendar year of operation of the Northern Ireland Tuberculosis Authority) until the end of 1952, there were 953 known recovered cases of tuberculosis. It was not possible to include all the recovered cases in the survey because of the time and cost involved, and instead a sample of 200 (91 males, 109 females) was selected by means of random numbers. To each of these individuals a letter, questionnaire, and business reply envelope were sent, followed-if necessary-by two reminder letters at fortnightly intervals. For various reasons 35 forms were not completed.*

Using the $\chi^{2}$ test for significance and adopting the conventional level of probability of $P<0.05$ (the criterion used throughout the report), no significant differences were found in respect of age, sex, tuberculosis

* Eleven persons failed to reply, six had emigrated, three had died, five stated that they had never had tuberculosis, four did not complete the form because of age or incapacity, and in six cases the correct address could not be traced. classification, and locality between the population of 953 persons from which the sample was drawn and:

(i) the 165 persons who replied, including nine children;

(ii) the $\mathbf{3 5}$ persons who failed to reply.

Persons who failed to reply differed, however, from those who did reply in respect of duration of illness, and this topic has not been studied.

In the following Tables the nine children (all under 12 years of age) have been excluded, leaving a final sample of 156 ( 74 males and 82 females; 131 pulmonary and 25 non-pulmonary).

\section{RESULTS}

A summary of the employment situation is given in Table I. Allowing that housework counts as an occupation, there was no significant difference between the two sexes in respect of numbers employed. Over 50 per cent. of the sample were gainfully employed (full or part-time), 28 per cent. were in unpaid work (housewives), and almost 20 per cent. were not working.

TABLE I

DISTRIBUTION OF SAMPLE MEMBERS BY SEX AND EMPLOYMENT

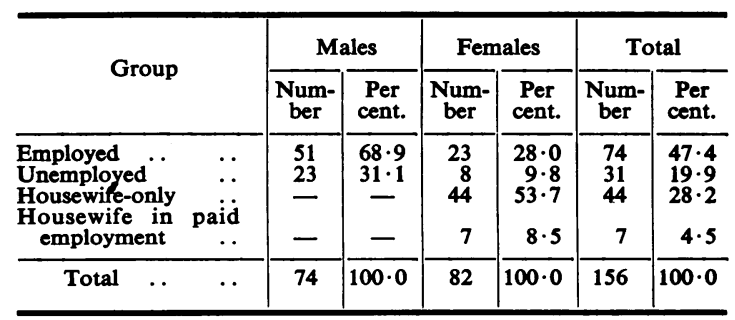

From the Ministry of Labour estimates (Ministry of Labour Gazette, 1953) it was calculated that approximately 297,600 insured men and 169,000 insured women in Northern Ireland were employed at the time of the survey and 33,500 insured men 
and 14,700 insured women were unemployed. Excluding five men and three women in the sample who were likely to be outside the scope of the National Insurance Scheme, the percentage of unemployed in the sample was 33.3 males and $28 \cdot 6$ females. These figures may be contrasted with $10 \cdot 1$ per cent. for unemployed males and 8 per cent. for unemployed females in the general population. It would appear, therefore, that the level of employment among "cured" tuberculous patients is much lower than the general level of employment in Northern Ireland.

Following the Ministry of Health's Classification (Ministry of Health, 1947), a comparison was made between "early" (A1) and "more advanced" (A2, 3; $\mathrm{B} 1,2,3)$ cases of pulmonary tuberculosis (Table II).

TABLE II

DISTRIB́UTION OF EMPLOYED AND UNEMPLOYED SAMPLE MEMBERS BY CLASSIFICATION OF DISEASE

\begin{tabular}{|c|c|c|c|}
\hline Classification & Employed & Unemployed & Total \\
\hline Early (A1) & 38 & 13 & 51 \\
\hline 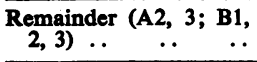 & 22 & 14 & 36 \\
\hline Total & 60 & 27 & $87^{*}$ \\
\hline
\end{tabular}

$x^{2}=1 \cdot 22, N=1,0 \cdot 30>P>0.20$

* Excluding eighteen cases of non-pulmonary tuberculosis.

Contrary to what might have been expected, the chronicity of the disease did not appear to have influenced the employment situation. There was, however, a slightly higher level of employment among the "early" cases ( 74.5 per cent) than among the remainder $(61 \cdot 1$ per cent.). The unemployed group comprised 48 per cent. A1 cases and 52 per cent. "more advanced" cases.

A comparison between the employed and unemployed persons in (a) urban and rural areas, and (b) Belfast and elsewhere, failed to reveal any significant difference. Though the findings are based on very small numbers, they suggest that place of domicile in Northern Ireland does not materially influence a tuberculous patient's opportunities for employment.

Information was obtained as to the general standard of education of the sample members (Table III). As might be expected there was a higher percentage of employment among persons who had obtained post-primary schooling, than among those who had only attended elementary schools, but the numbers are too small for the differences to be statistically significant.
TABLE III

DISTRIBUTION OF EMPLOYED AND UNEMPLOYED SAMPLE MEMBERS BY EDUCATION

\begin{tabular}{|c|c|c|c|c|c|}
\hline \multicolumn{3}{|c|}{ Education } & Employed & Unemployed & Total \\
\hline Primary. . & $\cdots$ & $\cdots$ & 48 & 25 & 73 \\
\hline Post-Primary & $\cdots$ & $\cdots$ & 26 & 6 & 32 \\
\hline Total & . & $\cdots$ & 74 & 31 & 105 \\
\hline
\end{tabular}

In Table IV all occupations placed by the Registrar - General (Registrar - General, 1951) in Social Classes I, II, IIIc, IIId, and IIIe are grouped together as "light" work and the remaining occupations (i.e. Social Classes IIIa, IIIb, IV, and V) as "heavy" work. In 21 cases (ten males and eleven females) no information about previous work was obtained, but for the 53 cases with records of preand post-illness employment, there was very little evidence of movement between "light" and "heavy" work. On the whole, the tendency was for patients to return either to the same or to a similar type of employment. In fact, in 34 cases, the occupation resumed after cure was identical with the one held before the patient became ill. This feature of the employment situation applied to all types and grades of work (e.g. agricultural and other labourers, managers, cutters, roundsmen, clerks, etc.).

TABLE IV

DISTRIBUTION OF EMPLOYED SAMPLE MEMBERS BY TYPE OF WORK BEFORE AND AFTER ILLNESS

\begin{tabular}{|c|c|c|c|c|c|}
\hline \multirow{5}{*}{$\begin{array}{l}\text { Work after } \\
\text { Illness }\end{array}$} & & \multicolumn{4}{|c|}{ Work before Illness } \\
\hline & & & Heavy & Light & Total \\
\hline & & Heavy .. & 15 & 4 & 19 \\
\hline & . & Light .. & 2 & 32 & 34 \\
\hline & & Total .. & 17 & 36 & 53 \\
\hline
\end{tabular}

Three persons failed to answer the question, "Do you find your work tiring?"; 25 answered in the affirmative and 46 gave negative replies. Of those who said they were tired, fifteen were in "light" and ten in "heavy" occupations. Of those who denied being tired by their work, 33 were in "light" and thirteen in "heavy" occupations. Because of the small numbers involved, it is impossible to draw any firm conclusions from these findings, but the fact that tiredness was slightly more common in the "heavy" occupations suggests that the two factors may be related.

The mean working week for men was $45 \cdot 8$ hours (i.e. just over 8 hours per day for $5 \frac{1}{2}$ days per week) 
with a standard deviation of $6 \cdot 80$. For the women in gainful employment, the mean was 43.3 hours and the standard deviation $10 \cdot 15$. There is, therefore, no significant difference between the sexes in the hours worked per week.

Only one of the 31 unemployed persons had any immediate prospect of returning to work. Five were not fit for any kind of work, nine desired full-time work, eleven would have been content with full or part-time work, four wanted part-time work only, and two did not answer the question. Three persons gave as their first choice their previous occupation, but although the group as a whole favoured sedentary jobs no single occupation emerged as favourite.

Replies were received from 51 married women. Of these 44 were doing housework only and seven combined housework with a paid job. The average number of persons in each household was 4.4 for housewives only, and three for housewives in paid work.

The housewives only averaged just over eight hours per day and the housewives in paid work averaged (outside the home) a 44-hour week.

Eleven of the housewives only expressed a desire for other employment, usually of a domestic nature. Only two of the housewives in paid employment admitted to having assistance with the housework. Although the numbers are small, it seems likely that the size of the family and the ability to procure domestic help are both important facts, in determining whether or not married women seek outside employment.

\section{SUMmaRY}

(1) The results of a postal survey of recovered tuberculous patients living in Northern Ireland are given. The object of the survey was to discover what happens to tuberculous patients when left free to find their own employment.
(2) Originally, the sample consisted of two hundred persons (drawn from a population of 953 known recovered cases), but for a number of reasons 44 were rejected or did not respond, thus leaving 156 persons (78 per cent.) who completed questionnaires.

(3) Of the 156 persons, 74 (47.4 per cent.) were employed, 31 (19.9 per cent.) were unemployed, and $51(32.7$ per cent.) were housewives.

(4) A much higher level of unemployment existed amongst ex-patients than in the community at large.

(5) The chronicity of the disease of the recovered tuberculous person did not appear to have any significant influence upon the employment situation.

(6) The place of domicile in Northern Ireland did not confer any particular advantage.

(7) On the whole, the tendency was for patierits to return either to the same or similar type of employment. This was the case in 64 per cent. of the employed persons.

(8) Of the unemployed persons, 80.7 per cent. had no prospects of securing any kind of work; the majority of this group expressed a desire for "light" work.

(9) Data were collected in respect of 51 housewives and of these 44 were occupied solely on housework, while seven had undertaken paid work in addition to their household duties.

(10) The survey suggests that almost one-quarter of all recovered cases require special assistance if they are to obtain suitable employment. Rehabilitation programmes for tuberculous patients should not overlook this.

\section{REFERENCES}

General Register Office (1951). "Classification of Occupations, 1950." H.M.S.O., London.

Ministry of Health (1925, rev. 1930, 1947). "Tuberculosis (England)". Memorandum 37/T.

Ministry of Labour (1953). Gazette (February), 61, 40. 